\title{
Colonic Stent Placement May Reduce Mortality Rate and Length of Hospitalization in Obstructive Colorectal Cancer Cases: a Propensity Score-matched Analysis Using a Nationwide Database in Japan
}

Rintaro Moroi ( $\nabla$ rinta@med.tohoku.ac.jp )

Tohoku University Graduate School of Medicine

Kunio Tarasawa

Tohoku University Graduate School of Medicine

Yusuke Shimoyama

Tohoku University Graduate School of Medicine

Masatake Kuroha

Tohoku University Graduate School of Medicine

Hisashi Shiga

Tohoku University Graduate School of Medicine

Yoichi Kakuta

Tohoku University Graduate School of Medicine

Kiyohide Fushimi

Tokyo Medical and Dental University Graduate School of Medicine

Kenji Fujimori

Tohoku University Graduate School of Medicine

Yoshitaka Kinouchi

Tohoku University Graduate School of Medicine

Atsushi Masamune

Tohoku University Graduate School of Medicine

\section{Research Article}

Keywords: Obstructive colorectal cancer, Self-expandable metallic stent, Urgent surgery

Posted Date: September 7th, 2021

DOI: https://doi.org/10.21203/rs.3.rs-864898/v1

License: (c) (i) This work is licensed under a Creative Commons Attribution 4.0 International License. Read Full License 


\section{Abstract}

Background and aims: Self-expandable metallic stent (SEMS) is widely used for obstructive colorectal cancer (OCC). Both SEMS and urgent surgery have several merits and demerits. This study aimed to clarify the efficacy of SEMS by comparing the mortality rate after the hospitalization between SEMS and urgent surgery for OCC.

Methods: We collected OCC patients' data using the Diagnosis Procedure Combination (DPC) database system. We divided eligible patients into the SEMS and urgent surgery groups using propensity score matching, and compared in-hospital death rates, length of hospitalization, and medical costs. We also conducted logistic regression analysis to identify clinical factors affecting in-hospital deaths.

Results: We enrolled 17,140 cases after propensity score matching. SEMS reduced the in-hospital death rate compared to urgent surgery $(2.0 \%$ vs. $3.6 \%, P<0.0001)$. Length of hospitalization was shorter in the SEMS group than in the urgent surgery group ( 16 vs. 25 days, $P<0.0001$ ). Medical costs were lower in the SEMS group than in the urgent surgery group $(1,663,550$ vs. $2,424,082 \mathrm{JPY}, P<0.0001)$. Multivariate analysis also showed that SEMS reduced in-hospital death (odds ratio $=0.58,95 \%$ confidence interval: $0.50-0.70, P<0.0001$ ).

Conclusion: SEMS placement for OCC could reduce the mortality rate and shorten the length of hospitalization. These results facilitate considering SEMS with careful judgement for its indication when treating OCC patients.

\section{Introduction}

Obstructive colorectal cancer (OCC) is an emergency situation which requires immediate decompression, and also shows high mortality and morbidity rates in the short and long-term. ${ }^{1}$ Approximately $10-30 \%$ of colorectal cancers develop colonic obstruction. ${ }^{2-5}$ One can select self-expandable metallic stent (SEMS) or urgent surgery when treating OCC. There are two major indications for placing SEMS: bridge to surgery (BTS) and palliation. SEMS placement demonstrates several merits, exhibiting good efficacy to release obstruction and safety in both BTS and palliation. ${ }^{6-8}$

On the contrary, the clinical guidelines from the European Society of Gastrointestinal Endoscopy recommends stenting as a bridge to surgery to be discussed. ${ }^{8}$ They also stated that BTS was a treatment option in patients with potentially curable left-sided OCC as an alternative to emergency resection. ${ }^{8}$ There are several randomized control trials (RCTs) which directly compared SEMS placement as BTS and urgent surgery in left-sided OCC. ${ }^{9-15}$ One RCT reported that the morbidity and three-year overall survival rates were not different in the two groups, while stoma creation rate in the BTS group was lower compared to urgent surgery group. ${ }^{15}$ Other RCTs also reported that there were no differences in the mortality rate ${ }^{10}$ and the length of hospitalization ${ }^{13}$ between SEMS and urgent surgery. Furthermore, another RCT concluded that SEMS has no clinical advantages over urgent surgery. ${ }^{12}$ However, these studies consisted of relatively small number of patients. It might be difficult to conduct a randomized control trial which contains enough number of patients to compare SEMS and urgent surgery because OCC is a severe disease that requires immediate intervention to release obstruction.

There is a national database of hospitalization in Japan, named the Diagnosis Procedure Combination (DPC). This database contains data of a large number of patients and could be an alternative method to investigate which strategy is preferable for OCC because of its high volume of data ${ }^{16,17}$ and by conducting propensity score matched analysis, instead of $\mathrm{RCT}^{18}$. 
This study aimed to investigate the efficacy of SEMS by comparing the mortality rate, length of hospitalization, and medical costs in the short-term, between SEMS and urgent surgery for OCC using a nationwide database in Japan.

\section{Methods}

\section{DPC system}

The DPC database, which has been in place since 2003, is a medical claims database of admissions to acute-care hospitals in Japan. The DPC system was adopted at 1730 hospitals in 2018 , and covers approximately $83 \%$ of the acute-care beds in Japan ${ }^{19}$. There are six distinct categories of diagnosis such as, "main diagnosis," "main disease triggering admission," "most resource-consuming diagnosis," "second most resource-consuming diagnosis," "comorbidities at admission," and "complications after admission" in the DPC database. The DPC database also contains patients' demographics, medical costs, procedures (including stent placement, colectomy, and ileostomy), and condition at discharge. ${ }^{20,21}$ The physicians input patients' diagnosis into the DPC database according to International Classification of Diseases, 10th revision (ICD-10). The DPC database has been used for various clinical studies,. ${ }^{16,18}$ including those for colorectal cancer, ${ }^{17}$ and its diagnostic validity is widely recognized. ${ }^{20}$

\section{Patients}

This study included patients with obstructive colorectal cancer who were admitted to DPC-participating hospitals from April 2012 through March 2020 (Fig. 1). Colorectal cancer was identified using the ICD-10 code C18-20, which indicates colon cancer or rectal cancer, as the most resource-consuming diagnosis. Entries of colorectal cancer suspicious cases containing the word "suspicious" were excluded. We included patients with the following characteristics, (1) primary colorectal cancer, (2) not scheduled or urgent admissions, (3) containing the phrase "ileus" as main disease triggering admission or comorbidities at admission. We selected conditions with not scheduled or urgent adomissions to exclude patients who were discharged after stent placement and underwent radical surgery after being readmitted. We finally extracted patients who underwent interventions to release obstructions within 3 days after admission.

\section{Data collection}

We collected the following data on patients and clinical characteristics, procedures, and condition at discharge from the DPC database: age, sex, body mass index (BMI), smoking history, Charlson comorbidity index (CCI), ${ }^{22}$ hospital type (academic hospital or not), tumor $(T)$ categories based on TNM classification, ${ }^{23}$ disease location (including cecum, ascending colon, transverse colon, descending colon, sigmoid colon, and rectum), condition at discharge (inhospital death), medical costs (available data from 2016 to 2020), length of the hospital stay, and interventions to release obstruction such as SEMS placement and surgery (including colectomy and/or stoma creation). We defined in-hospital death, medical costs and the length of the hospital stay as clinical endpoints to evaluate the efficacy of SEMS.

\section{Data analysis}

We classified the eligible patients into five categories according to their age ( $\leq 49$ years, $50-59$ years, $60-69$ years, 70-79 years, $\geq 80$ years) and into three categories according to body mass index (BMI) (underweight: $<18.5 \mathrm{~kg} / \mathrm{m}^{2}$, normal range: $18.5-24.9 \mathrm{~kg} / \mathrm{m}^{2}$, overweight: $>25.0 \mathrm{~kg} / \mathrm{m}^{2}$ ) based on the World Health Organization classification. ${ }^{24}$ The eligible patients were also divided into two groups according to the intervention to release obstruction due to 
obstructive colorectal cancer, as follows: SEMS group (stent placement) and surgery group (colectomy and/or stoma creation). The DPC database does not include the time of admission; thus, only the date of admission was recorded. Therefore, we extracted interventions which were conducted within 3 days after admission.

We conducted propensity score matching analysis to compare the efficacy of stent placement with that of surgery. We used the following variables for propensity score matching: sex, age categories, and BMI categories as described above, $\mathrm{CCl}$, smoking history, hospital type, T categories and disease location. We subsequently compared them using rates of in-hospital death between the SEMS and surgery groups, using chi-square tests, and the length of hospitalization and medical costs of hospital stay, using Wilcoxon's signed-rank test. The eligible patients after propensity score matching were divided into two groups based on the disease location, as follows: right-sided colon consisted of cecum, ascending and transverse colon, left-sided colon consisted of descending and sigmoid colon and rectum. We then compared the rate of in-hospital death, length of hospitalization, and medical costs in each group as well. We also performed a multivariate analysis using logistic regression analysis with the data before propensity score matching to identify clinical factors that affect in-hospital death.

\section{Statistics}

The threshold for statistical significance was $P<0.05$. All analyses were performed using JMP Pro14 (SAS institute, Tokyo, Japan) software. All authors had access to the study data and reviewed and approved the final manuscript.

\section{Ethics}

The current study was conducted in accordance with the ethical standards of the Declaration of Helsinki. The study protocol was reviewed and approved by the Ethics Committee of Tohoku University Graduate School of Medicine (2019-1-415). Owing to the anonymous nature of the data, informed consent was waived for the approval of the Ethics Committee of Tohoku University Graduate School of Medicine (2019-1-415).

\section{Results}

\section{Patient characteristics}

We finally included 20968 eligible cases, of whom 10877 were assigned to the SEMS group, and the remaining 10091 to the surgery group (Fig. 1). After propensity score matching, 8570 pairs of patients were selected. The Cstatistic was 0.63 , and the standardized difference in each variable was $<0.1$. The characteristics of the study population are summarized in Table 1. The characteristics of both groups were similar after propensity score matching.

\section{Comparisons of clinical endpoints between SEMS and surgery groups after propensity score matching}

The relationship between intervention type and clinical endpoints is summarized in Table 2. The rate of in-hospital death was lower in the SEMS group than in the surgery group $(2.0 \%$ vs. $3.6 \%, P<0.0001)$. The median length of hospital stay in the SEMS group was shorter than that in the surgery group (16 days vs. 25 days, $P<0.0001$ ). The medical costs of hospital stay in the SEMS group was lower than that in the surgery group $(1,663,550 \mathrm{JPY}$ vs.

$2,424,082$ JPY, $P<0.0001)$.

\section{Comparisons of clinical endpoints between SEMS and surgery in the right-sided colon}


The relationship between intervention type and clinical endpoints in the right-sided colon are summarized in Table 3. The rate of in-hospital death was lower in the SEMS group than in the surgery group $(1.9 \% \mathrm{vs.} 4.1 \%, \mathrm{P}<0.0001)$. The median length of hospital stay in the SEMS group was shorter than that in the surgery group (15 days vs. 21 days, $\mathrm{P}$ $<0.0001)$. The medical costs of hospital stay in the SEMS group was lower than that in the surgery group $(1,642,437$ JPY vs. 2,448,512 JPY, $\mathrm{P}<0.0001)$.

\section{Comparison of clinical endpoints between SEMS and surgery in the left-sided colon}

The relationship between intervention type and clinical endpoints in the left-sided colon are summarized in Table 4. The rate of in-hospital death was lower in the SEMS group than in the surgery group $(2.1 \% \mathrm{vs.} 3.4 \%, P<0.0001)$. The median length of hospital stay in the SEMS group was shorter than that in the surgery group (16 days vs. 26 days, $P$ $<0.0001)$. The medical costs of hospital stay in the SEMS group were lower than that in the surgery group $(1,681,960$ JPY vs. $2,415,350$ JPY, $P<0.0001)$.

\section{Multivariate analysis for in-hospital death before propensity score matching}

The results of multivariate analysis for in-hospital death are summarized in Table 5. On multivariate analysis, Female (odds ratio $[\mathrm{OR}]=0.82,95 \%$ confidence interval [Cl]: 0.69-0.99, $\mathrm{P}=0.041$ ), younger age, academic hospital $(\mathrm{OR}=0.6,95 \% \mathrm{Cl}: 0.37-0.99, \mathrm{P}=0.043)$, and stent placement $(\mathrm{OR}=0.58,95 \% \mathrm{Cl}: 0.50-0.70, \mathrm{P}<0.0001)$ were identified as the clinical factors that decrease in-hospital death. Conversely, underweight $(\mathrm{OR}=1.51,95 \% \mathrm{Cl}$ : $1.24-$ $1.85, \mathrm{P}<0.0001)$ and 2 or more points of $\mathrm{CCl}$ were identified as the clinical factors that increase in-hospital death.

\section{Discussion}

In this study, we investigated the efficacy of SEMS comparing with urgent surgery for OCC using a nationwide database in Japan. Our propensity score-matched analysis revealed that the in-hospital death rate of the SEMS group was lower than that of urgent surgery. The length of the hospitalization and medical costs of SEMS group was shorter and lower than that of urgent surgery as well. This study also showed the same results in both right and left-sided OCC. Multivariate analysis using the data before propensity score matching also showed lower odds ratio of SEMS compared to urgent surgery in the in-hospital death.

OCC is an emergency disease which requires immediate intervention to release bowel obstruction. Both SEMS and urgent surgery have several merits and demerits. Therefore, it is important to investigate which treatment is preferable for OCC. Our study, which consisted of a large number of patients and used propensity score matched analysis, showed the lower rate of in-hospital death in SEMS group compared to urgent surgery group. The chisquare test after propensity score matching and multivariate analysis before propensity score matching revealed that SMES placement reduced in-hospital death. Our results indicate that SEMS could reduce mortality rate due to OCC in the short-term. On the contrary, previous RCTs comparing SEMS and urgent surgery in left-sided OCC ${ }^{9-15}$ showed that their results were inconsistent regarding the priority of SEMS to urgent surgery. Although RCT is the best investigation method to clarify which treatment is prefer, these studies contain small number of patients. The discrepancy among these studies might be because of the relatively small number of patients included in each study. A meta-analysis demonstrated tendencies similar to our results. ${ }^{25}$ To the best of our knowledge, no previous study has reported an association between SEMS placement and reduction of in-hospital death. A nationwide database like DPC would be useful for investigations of rare complications and diseases with its a large number of patients. Furthermore, urgent surgery is associated with higher rates of morbidity and mortality compared to the 
elective surgery. ${ }^{26-28}$ SEMS placement as a BTS could reduce such unfavorable events with releasing obstruction which contribute to avoid urgent surgery.

The impact of the difference of obstruction site on the clinical outcome is still unclear. Our data also showed that SEMS placement reduced the rates of the in-hospital death in both right and left-sided OCC. This result could indicate that SEMS placement for left-sided OCC could, in turn, reduce the mortality rate in the short-term as well as for right-sided OCC. Therefore, we should consider SEMS placement for left-sided OCC. Furthermore, studies about SEMS placement for the right-sided OCC are rare. Our results also demonstrated clinical effectiveness of SEMS for right-sided OCC. Even if an OCC is located in both side, SEMS placement could be worth of considering.

The guideline of European Society of Gastrointestinal Endoscopy recommends stenting as a BTS in left-sided colon to be discussed. ${ }^{8}$ We agree with this opinion because SEMS placement is not suitable for all OCC cases. For instance, urgent surgery should be performed in OCC cases with perforation, abscess formation and obstructive colitis. However, we think SEMS placement should be proactively considered for the OCC cases without such complication because SEMS placement could reduce in-hospital death.

There are several benefits of SEMS. The length of the hospitalization and medical costs of SEMS were shorter and lower than those of urgent surgery. Several studies showed similar tendency as well. ${ }^{10} \mathrm{~A}$ retrospective study in Japan reported that SEMS showed lower complication rates compared to urgent surgery. ${ }^{29}$ These results indicate SEMS could reduce complication after intervention compared to urgent surgery, which contribute to shorten the length of hospitalization and to decrease the medical costs.

SEMS placement has another benefit enabling us to avoid creating stoma. Several RCTs comparing SEMS placement and urgent surgery reported lower stoma creation rate in SEMS groups. ${ }^{11,12,15}$ The patients with OCC will not need to undertake stoma creation due to the success of decompression using SEMS. In terms of quality of life, intervention without creating stoma is favorable.

Although SEMS placement for OCC has several benefits, its indication should be discussed adequately. As described above, OCC cases with complications such as complex or elongated stenosis, hemorrhage, perforation, or severe inflammation which indicate obstructive colitis should undertake urgent surgery rather than SEMS placement ${ }^{30}$ because such cases are expected to go to fatal results. Obstructive colitis due to colon cancer develops ulceroinflammatory lesions which might be a cause of septicemia, perforation and subsequent peritonitis. ${ }^{31}$

There is a similar study reported that the postoperative hospital stay was shorter in the emergency surgery cases and postoperative ileus was more common in the SEMS group in the left-sided OCC. ${ }^{32}$ They also analyzed the DPC data and there seems to be discrepancy between our and their results. This discrepancy might due to the difference of analysis method and endpoints in each study. Further investigations are warranted.

There are several limitations in this study. First, the DPC database does not contain details of the patients' condition, such as endoscopic findings, laboratory data, and computed tomography findings. For instance, our result includes T1 or T2 cases. T1 or T2 cases usually don't develop OCC. However, we included such cases because we selected cases who were expected to developed OCC using conditions containing the phrase "ileus" and intervention within 3 days after admission. Complications including obstructive colitis is also diagnosed using clinical data, and we usually select urgent surgery instead of SEMS placement for such cases. Although we conducted a propensity score match to make the patients' backgrounds between the two groups, the possibility of selection bias cannot be denied. Second, the DPC database does not contain long-term data. We herein analyzed the short-term results; we need to 
conduct a prospective or retrospective study to clarify the long-term prognosis. Third, the DPC database can't distinguish the purpose of SEMS placement between BTS and palliation, and thus, our analysis contains both BTS and palliation cases. However, our results demonstrated that SEMS placement could contribute to decrease in mortality rate, whether the case is BTS or palliation. Although there are several limitations in this study, our results indicate that when both SEMS placement and urgent surgery are suitable for OCC, SEMS placement might be better than urgent surgery.

In conclusion, SEMS placement for OCC could reduce the mortality rate and shorten the length of hospitalization. These results facilitate considering SEMS with careful judgement for its indication when we treat OCC.

\section{Abbreviations}

BTS: bridge to surgery

DPC: Diagnosis Procedure Combination

OCC: obstructive colorectal cancer

RCT: randomized control trial

SEMS: self-expandable metallic stent

\section{Declarations}

\section{Funding:}

The current study was self-funded.

\section{Conflicts of interest:}

The authors declare that they have no conflict of interest.

\section{Availability of data and material:}

Not applicable

\section{Code availability:}

Not applicable

\section{Author contributions:}

R. M, Y. S, M. K, H. S and Y. Kakuta contributed to the study conception and design. Material preparation, data collection and analysis were performed by R. M, K. T, K. Fujimori and K. Fushimi. The first draft of the manuscript was written by $\mathrm{R} M$ and revised critically by $\mathrm{Y}$. Kunouchi and $\mathrm{A}$. M. All authors read and approved the final version of the manuscript.

\section{Ethics approval:}


The study protocol was reviewed and approved by the Ethics Committee of Tohoku University Graduate School of Medicine (2019-1-415).

\section{Consent to participate and Consent for publication:}

Owing to the anonymous nature of the data, informed consent was waived for the approval.

\section{Acknowledgements:}

None

\section{Referenes}

1. Biondo, S. et al. Large bowel obstruction: predictive factors for postoperative mortality. Diseases of the colon and rectum 47, 1889-1897, doi:10.1007/s10350-004-0688-7 (2004).

2. Ohman, U. [Decreased operative mortality in colorectal cancer but unchanged therapeutic results during 30-40 years]. Lakartidningen 79, 1001-1004 (1982).

3. Phillips, R. K., Hittinger, R., Fry, J. S. \& Fielding, L. P. Malignant large bowel obstruction. The British journal of surgery 72, 296-302 (1985).

4. Carraro, P. G., Segala, M., Cesana, B. M. \& Tiberio, G. Obstructing colonic cancer: failure and survival patterns over a ten-year follow-up after one-stage curative surgery. Diseases of the colon and rectum 44, 243-250 (2001).

5. Okuda, Y. et al. Colorectal obstruction is a potential prognostic factor for stage II colorectal cancer. Int J Clin Oncol 23, 1101-1111, doi:10.1007/s10147-018-1307-2 (2018).

6. Ohki, T. et al. Determining the difference in the efficacy and safety of self-expandable metallic stents as a bridge to surgery for obstructive colon cancer among patients in the CROSS 0 group and those in the CROSS 1 or 2 group: a pooled analysis of data from two Japanese prospective multicenter trials. Surg Today 50, 984-994, doi:10.1007/s00595-020-01970-3 (2020).

7. Tomita, M. et al. Self-expandable metallic stenting as a bridge to surgery for malignant colorectal obstruction: pooled analysis of 426 patients from two prospective multicenter series. Surgical endoscopy 33, 499-509, doi:10.1007/s00464-018-6324-8 (2019).

8. Veld, J. et al. Self-expandable metal stent (SEMS) placement or emergency surgery as palliative treatment for obstructive colorectal cancer: A systematic review and meta-analysis. Crit Rev Oncol Hematol 155, 103110, doi:10.1016/j.critrevonc.2020.103110 (2020).

9. Cheung, H. Y. et al. Endolaparoscopic approach vs conventional open surgery in the treatment of obstructing left-sided colon cancer: a randomized controlled trial. Arch Surg 144, 1127-1132, doi:10.1001/archsurg.2009.216 (2009).

10. Ho, K. S., Quah, H. M., Lim, J. F., Tang, C. L. \& Eu, K. W. Endoscopic stenting and elective surgery versus emergency surgery for left-sided malignant colonic obstruction: a prospective randomized trial. Int J Colorectal Dis 27, 355-362, doi:10.1007/s00384-011-1331-4 (2012).

11. Pirlet, I. A., Slim, K., Kwiatkowski, F., Michot, F. \& Millat, B. L. Emergency preoperative stenting versus surgery for acute left-sided malignant colonic obstruction: a multicenter randomized controlled trial. Surgical endoscopy 25, 1814-1821, doi:10.1007/s00464-010-1471-6 (2011).

12. van Hooft, J. E. et al. Colonic stenting versus emergency surgery for acute left-sided malignant colonic obstruction: a multicentre randomised trial. Lancet Oncol 12, 344-352, doi:10.1016/s1470-2045(11)70035-3 
(2011).

13. Alcántara, M. et al. Prospective, controlled, randomized study of intraoperative colonic lavage versus stent placement in obstructive left-sided colonic cancer. World J Surg 35, 1904-1910, doi:10.1007/s00268-011-1139-y (2011).

14. Ghazal, A. H., El-Shazly, W. G., Bessa, S. S., El-Riwini, M. T. \& Hussein, A. M. Colonic endolumenal stenting devices and elective surgery versus emergency subtotal/total colectomy in the management of malignant obstructed left colon carcinoma. J Gastrointest Surg 17, 1123-1129, doi:10.1007/s11605-013-2152-2 (2013).

15. Arezzo, A. et al. Colonic stenting as a bridge to surgery versus emergency surgery for malignant colonic obstruction: results of a multicentre randomised controlled trial (ESCO trial). Surgical endoscopy 31, 3297-3305, doi:10.1007/s00464-016-5362-3 (2017).

16. Yasunaga, H. et al. Relationship between hospital volume and operative mortality for liver resection: Data from the Japanese Diagnosis Procedure Combination database. Hepatol Res 42, 1073-1080, doi:10.1111/j.1872034X.2012.01022.x (2012).

17. Tajima, T. et al. Open colectomy vs. laparoscopic colectomy in Japan: a retrospective study using real-world data from the diagnosis procedure combination database. Surg Today 50, 1255-1261, doi:10.1007/s00595-02002006-6 (2020).

18. Moroi, R. et al. Efficacy of urgent colonoscopy for colonic diverticular bleeding: A propensity score-matched analysis using a nationwide database in Japan. Journal of gastroenterology and hepatology 36, 1598-1604, doi:10.1111/jgh.15316 (2021).

19. https://www.mhlw.go.jp/file/06-Seisakujouhou-12400000-Hokenkyoku/0000197983.pdf (In Japanese).

20. Yamana, H. et al. Validity of diagnoses, procedures, and laboratory data in Japanese administrative data. $J$ Epidemiol 27, 476-482, doi:10.1016/j.je.2016.09.009 (2017).

21. Fujimoto, S. \& Nakayama, T. Effect of combination of pre- and postoperative pulmonary rehabilitation on onset of postoperative pneumonia: a retrospective cohort study based on data from the diagnosis procedure combination database in Japan. Int J Clin Oncol 24, 211-221, doi:10.1007/s10147-018-1343-y (2019).

22. Charlson, M. E., Pompei, P., Ales, K. L. \& MacKenzie, C. R. A new method of classifying prognostic comorbidity in Iongitudinal studies: development and validation. J Chronic Dis 40, 373-383, doi:10.1016/0021-9681(87)901718 (1987).

23. UICC. TNM Classification of Malignant Tumours 8th edn. (2017).

24. Bojesen, R. D., Riis, L. B., Høgdall, E., Nielsen, O. H. \& Jess, T. Inflammatory Bowel Disease and Small Bowel Cancer Risk, Clinical Characteristics, and Histopathology: A Population-Based Study. Clinical gastroenterology and hepatology : the official clinical practice journal of the American Gastroenterological Association 15, 19001907.e1902, doi:10.1016/j.cgh.2017.06.051 (2017).

25. Arezzo, A. et al. Stent as bridge to surgery for left-sided malignant colonic obstruction reduces adverse events and stoma rate compared with emergency surgery: results of a systematic review and meta-analysis of randomized controlled trials. Gastrointestinal endoscopy 86, 416-426, doi:10.1016/j.gie.2017.03.1542 (2017).

26. Yang, Z. et al. Clinicopathologic characteristics and outcomes of patients with obstructive colorectal cancer. $J$ Gastrointest Surg 15, 1213-1222, doi:10.1007/s11605-011-1563-1 (2011).

27. Lelcuk, S. et al. Endoscopic decompression of acute colonic obstruction. Avoiding staged surgery. Annals of surgery 203, 292-294, doi:10.1097/00000658-198603000-00013 (1986). 
28. Smothers, L. et al. Emergency surgery for colon carcinoma. Diseases of the colon and rectum 46, 24-30, doi:10.1007/s10350-004-6492-6 (2003).

29. Endo, S. et al. Comparison of survival and perioperative outcome of the colonic stent and the transanal decompression tube placement and emergency surgery for left-sided obstructive colorectal cancer: a retrospective multi-center observational study "The CODOMO study". Int J Colorectal Dis 36, 987-998, doi:10.1007/s00384-020-03806-5 (2021).

30. Saida, Y. Current status of colonic stent for obstructive colorectal cancer in Japan; a review of the literature. $J$ Anus Rectum Colon 3, 99-105, doi:10.23922/jarc.2019-009 (2019).

31. Tsai, M. H., Yang, Y. C. \& Leu, F. J. Obstructive colitis proximal to partially obstructive colonic carcinoma: a case report and review of the literature. Int J Colorectal Dis 19, 268-272, doi:10.1007/s00384-003-0558-0 (2004).

32. Katsuki, R., Jo, T., Yasunaga, H., Ishimaru, M. \& Sakamoto, T. Outcomes of self-expandable metal stent as bridge to surgery versus emergency surgery for left-sided obstructing colon cancer: A retrospective cohort study. American journal of surgery 221, 168-173, doi:10.1016/j.amjsurg.2020.06.012 (2021).

\section{Tables}


Table 1

Comparison of clinical characteristics of study population between before and after propensity score matching

\begin{tabular}{|c|c|c|c|c|c|c|c|}
\hline & \multicolumn{3}{|c|}{$\begin{array}{l}\text { Before propensity score matching } \\
\text { Total } n=20968\end{array}$} & \multicolumn{4}{|c|}{ After propensity score matching Total $n=17140$} \\
\hline & $\begin{array}{l}\text { SEMS } \\
\text { goup } n= \\
10877\end{array}$ & $\begin{array}{l}\text { Surgery } \\
\text { group } \mathrm{n}= \\
10091\end{array}$ & $\begin{array}{l}P \\
\text { value }\end{array}$ & $\begin{array}{l}\text { SEMS } \\
\text { group } n= \\
8570\end{array}$ & $\begin{array}{l}\text { Surgery } \\
\text { group } n= \\
8570\end{array}$ & $P$ value & $\begin{array}{l}\text { Standardized } \\
\text { difference }\end{array}$ \\
\hline $\begin{array}{l}\text { Sex } \\
\text { (male/female) }\end{array}$ & $5993 / 4884$ & $5165 / 4926$ & $\begin{array}{l}<.0001 \\
0.000\end{array}$ & $4561 / 4009$ & $4552 / 4018$ & 0.90 & 0.0021 \\
\hline $\begin{array}{l}\text { Age (mean } \pm \\
\text { SD), years }\end{array}$ & $73.5 \pm 12.3$ & $73.2 \pm 12.8$ & 0.13 & $73.3 \pm 12.4$ & $73.2 \pm 12.6$ & 0.64 & 0.008 \\
\hline \multicolumn{8}{|l|}{$\begin{array}{l}\text { Age } \\
\text { categories }\end{array}$} \\
\hline$\geq 80$ years & 3714 & 3537 & & 2919 & 2939 & & \\
\hline 70-79 years & 3263 & 2773 & & 2481 & 2450 & & \\
\hline $60-69$ years & 2593 & 2404 & & 2069 & 2068 & & \\
\hline $50-59$ years & 854 & 932 & & 753 & 754 & & \\
\hline$\leq 49$ years & 453 & 445 & & 348 & 359 & & \\
\hline $\begin{array}{l}\text { Body mass } \\
\text { index (mean } \pm \\
S D), \mathrm{kg} / \mathrm{m}^{2}\end{array}$ & $21.4 \pm 4.8$ & $20.8 \pm 3.9$ & $\begin{array}{l}<.0001 \\
0.000\end{array}$ & $21.1 \pm 4.7$ & $21.0 \pm 3.9$ & 0.05 & 0.023 \\
\hline \multicolumn{8}{|l|}{$\begin{array}{l}\text { BMI } \\
\text { categories }\end{array}$} \\
\hline $\begin{array}{l}\text { Overweight (> } \\
\left.25.0 \mathrm{~kg} / \mathrm{m}^{2}\right)\end{array}$ & 1532 & 1095 & & 986 & 1022 & & \\
\hline $\begin{array}{l}\text { Normal range } \\
(18.5-24.9 \\
\left.\mathrm{kg} / \mathrm{m}^{2}\right)\end{array}$ & 6554 & 5839 & & 5125 & 5070 & & \\
\hline $\begin{array}{l}\text { Under weight } \\
\left(<18.5 \mathrm{~kg} / \mathrm{m}^{2}\right)\end{array}$ & 2108 & 2472 & & 1919 & 1914 & & \\
\hline $\begin{array}{l}\text { Charlson } \\
\text { Comorbidity } \\
\text { Index score } \\
\text { (mean } \pm \text { SD) }\end{array}$ & $1.5 \pm 2.2$ & $1.6 \pm 2.3$ & $<.0001$ & $1.6 \pm 2.3$ & $1.6 \pm 2.3$ & 0.25 & 0 \\
\hline $\begin{array}{l}\text { Smoking } \\
\text { history } \\
\text { (yes/no) }\end{array}$ & $3429 / 7448$ & $3005 / 7086$ & 0.0064 & $2598 / 5972$ & $2638 / 5932$ & 0.52 & 0.010 \\
\hline $\begin{array}{l}\text { Academic } \\
\text { hospital } \\
\text { (yes/no) }\end{array}$ & $405 / 10472$ & 614/9477 & $\begin{array}{l}< \\
0.0001\end{array}$ & $391 / 8179$ & $380 / 8190$ & 0.71 & 0.0062 \\
\hline T categories & & & $\begin{array}{l}<.0001 \\
0 .\end{array}$ & & & 0.84 & \\
\hline
\end{tabular}




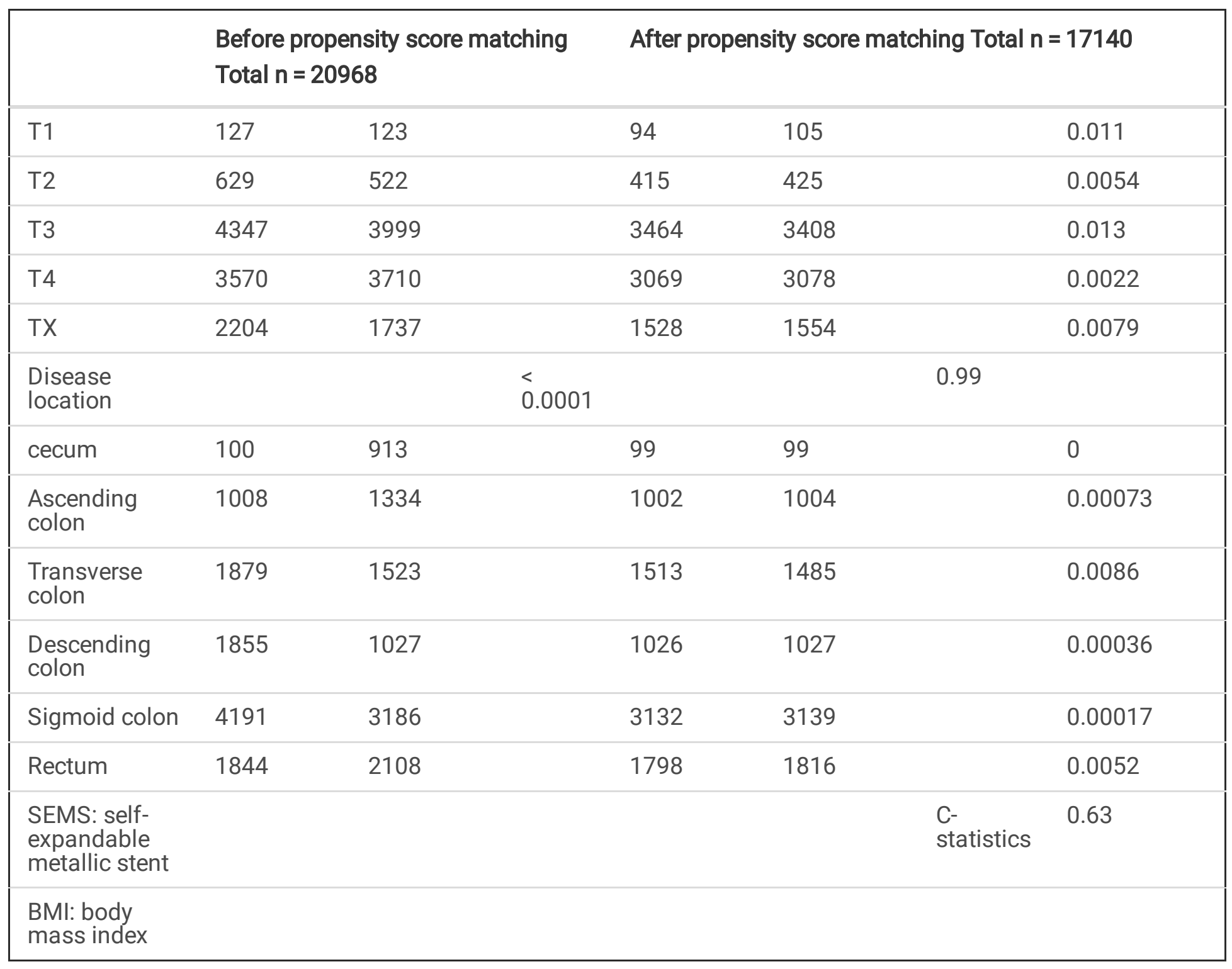


Table 2

Comparison of clinical outcomes between stent placement and surgery in study population

\begin{tabular}{|c|c|c|c|}
\hline & \multicolumn{3}{|c|}{ After propensity score matching Total $(n=17140)$} \\
\hline Clinical outcomes & $\begin{array}{l}\text { SEMS group }(n= \\
8570)\end{array}$ & $\begin{array}{l}\text { Surgery group }(n= \\
8570)\end{array}$ & $P$ value \\
\hline In-hospital death, n (\%) & $172(2.0 \%)$ & $312(3.6 \%)$ & $<0.0001$ * \\
\hline $\begin{array}{l}\text { Median days of hospital stay } \\
\text { (interquartile range), days }\end{array}$ & $16(9-29)$ & $25(16-38)$ & $<0.0001 * \star$ \\
\hline $\begin{array}{l}\text { Median medical costs of hospital stay } \\
\text { (interquartile range), JPY }\end{array}$ & $\begin{array}{l}1,663,550(977,390- \\
2,722,356) \star \star \star \star\end{array}$ & $\begin{array}{l}2,424,082(1,566,334- \\
3,577,815) \star \star \star \star \star\end{array}$ & $<0.0001 * \star$ \\
\hline \multirow[t]{4}{*}{ SEMS: self-expandable metallic stent } & & & *: chi-square test \\
\hline & & & $\begin{array}{l}\star \star \text { : Wilcoxon } \\
\text { signed-rank test }\end{array}$ \\
\hline & & & $\star \star \star n=5995$ \\
\hline & & & 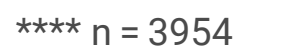 \\
\hline
\end{tabular}

Table 3

Comparison of clinical outcomes between stent placement and surgery in patients with obstructive right-sided colon cancer

\begin{tabular}{|c|c|c|c|}
\hline & \multicolumn{3}{|c|}{$\begin{array}{l}\text { Right-sided colon cancer cases after propensity score matching ( } \mathrm{n}= \\
\text { 5202) }\end{array}$} \\
\hline Clinical outcomes & $\begin{array}{l}\text { SEMS group }(\mathrm{n}= \\
2614)\end{array}$ & $\begin{array}{l}\text { Surgery group }(n= \\
2588)\end{array}$ & $P$ value \\
\hline In-hospital death, n (\%) & $49(1.9 \%)$ & $106(4.1 \%)$ & $<0.0001$ * \\
\hline $\begin{array}{l}\text { Median days of hospital stay } \\
\text { (interquartile range), days }\end{array}$ & $15(9-28)$ & $21(14-34)$ & $<0.0001$ ** \\
\hline $\begin{array}{l}\text { Median medical costs of hospital stay } \\
\text { (interquartile range), JPY }\end{array}$ & $\begin{array}{l}1,642,437 \\
(1004229-2632060)\end{array}$ & $\begin{array}{l}2,448,512(1,591,211- \\
3,407,600) \star \star \star \star\end{array}$ & $<0.0001 * \star$ \\
\hline \multirow[t]{4}{*}{ SEMS: self-expandable metallic stent } & & & *: chi-square test \\
\hline & & & $\begin{array}{l}\star * \text { : Wilcoxon } \\
\text { signed-rank test }\end{array}$ \\
\hline & & & $\star \star \star n=1874$ \\
\hline & & & $\star \star \star \star ~ n=1189$ \\
\hline
\end{tabular}


Table 4

Comparison of clinical outcomes between stent placement and surgery in patients with obstructive left-sided colorectal cancer

\begin{tabular}{|c|c|c|c|}
\hline & \multicolumn{3}{|c|}{$\begin{array}{l}\text { Left-sided colorectal cancer cases after propensity score matching ( } \\
=11938)\end{array}$} \\
\hline Clinical outcomes & $\begin{array}{l}\text { SEMS group }(\mathrm{n}= \\
5956)\end{array}$ & $\begin{array}{l}\text { Surgery group }(n= \\
5982)\end{array}$ & $P$ value \\
\hline In-hospital death, n (\%) & $123(2.1 \%)$ & $206(3.4 \%)$ & $<0.0001$ * \\
\hline $\begin{array}{l}\text { Median days of hospital stay } \\
\text { (interquartile range), days }\end{array}$ & $16(9-30)$ & $26(18-40)$ & $<0.0001$ ** \\
\hline $\begin{array}{l}\text { Median medical costs of hospital stay } \\
\text { (interquartile range), JPY }\end{array}$ & $\begin{array}{l}1,681,960(974,687- \\
2,749,383) * \star \star\end{array}$ & $\begin{array}{l}2,415,350(1,557,545- \\
3,665,824) * \star \star \star\end{array}$ & $<0.0001$ ** \\
\hline \multirow[t]{4}{*}{ SEMS: self-expandable metallic stent } & & & *: chi-square test \\
\hline & & & $\begin{array}{l}* * \text { : Wilcoxon } \\
\text { signed-rank test }\end{array}$ \\
\hline & & & $\star \star \star ~ n=5515$ \\
\hline & & & $\star \star \star \star \star ~ n=2929$ \\
\hline
\end{tabular}


Table 5

Multivariate analysis* of the association among clinical factors and in-hospital death

\begin{tabular}{|c|c|c|c|c|}
\hline \multirow[t]{2}{*}{ Clinical factors } & \multirow{2}{*}{$\begin{array}{l}\text { Number of patients (before propensity } \\
\text { score matching) }\end{array}$} & \multicolumn{3}{|c|}{ In-hospital death } \\
\hline & & $\begin{array}{l}\text { Odds } \\
\text { ratio }\end{array}$ & $95 \% \mathrm{Cl}$ & $\begin{array}{l}\mathrm{p} \text { - } \\
\text { value }\end{array}$ \\
\hline \multirow[t]{2}{*}{ Sex } & Male : 11158 & 1 & & \multirow[t]{2}{*}{0.041} \\
\hline & Female : 9810 & 0.82 & $\begin{array}{l}0.69- \\
0.99\end{array}$ & \\
\hline \multirow[t]{5}{*}{ Age categories } & $\geq 80$ years: 7251 & 1 & & \\
\hline & 70-79 years: 6036 & 0.47 & $\begin{array}{l}0.38- \\
0.58\end{array}$ & $<.0001$ \\
\hline & 60-69 years: 4997 & 0.37 & $\begin{array}{l}0.29- \\
0.47\end{array}$ & $<.0001$ \\
\hline & 50-59 years: 1786 & 0.27 & $\begin{array}{l}0.18- \\
0.42\end{array}$ & $\begin{array}{l}<.0001 \\
0.00\end{array}$ \\
\hline & $\leq 49$ years: 898 & 0.27 & $\begin{array}{l}0.14- \\
0.50\end{array}$ & $<.0001$ \\
\hline \multirow[t]{3}{*}{ BMI classsificatioin } & Overweight: 2627 & 1.11 & $\begin{array}{l}0.83- \\
1.48\end{array}$ & 0.48 \\
\hline & Normal: 12393 & 1 & & \\
\hline & Underweight: 4580 & 1.51 & $\begin{array}{l}1.24- \\
1.85\end{array}$ & $<.0001$ \\
\hline \multirow[t]{2}{*}{ Smoking history } & Yes: 6434 & 1.08 & $\begin{array}{l}0.88- \\
1.32\end{array}$ & \multirow[t]{2}{*}{0.46} \\
\hline & No: 14534 & 1 & & \\
\hline \multirow[t]{2}{*}{ Academic Hospital } & Yes: 1019 & 0.6 & $\begin{array}{l}0.37- \\
0.99\end{array}$ & 0.043 \\
\hline & No: 19949 & 1 & & \\
\hline \multirow[t]{2}{*}{$\begin{array}{l}\text { Chralson comobidity index score ( } 2 \\
\text { or more points) }\end{array}$} & Yes: 6337 & 1.75 & $\begin{array}{l}1.48- \\
2.06\end{array}$ & $\begin{array}{l}<.0001 \\
0.01\end{array}$ \\
\hline & No: 14631 & 1 & & \\
\hline \multirow[t]{2}{*}{ Intervention } & Stent placement : 10877 & 0.58 & $\begin{array}{l}0.50- \\
0.70\end{array}$ & \multirow[t]{2}{*}{$<0.0001$} \\
\hline & Surgery : 10091 & 1 & & \\
\hline \multirow[t]{3}{*}{ Disease location } & Right-sided : 6757 & 0.90 & $\begin{array}{l}0.75- \\
1.07\end{array}$ & \multirow[t]{2}{*}{0.24} \\
\hline & Left-sided : 14211 & 1 & & \\
\hline & & $\begin{array}{l}* \text { : Logi } \\
\text { analys }\end{array}$ & egression & \\
\hline
\end{tabular}


Figures

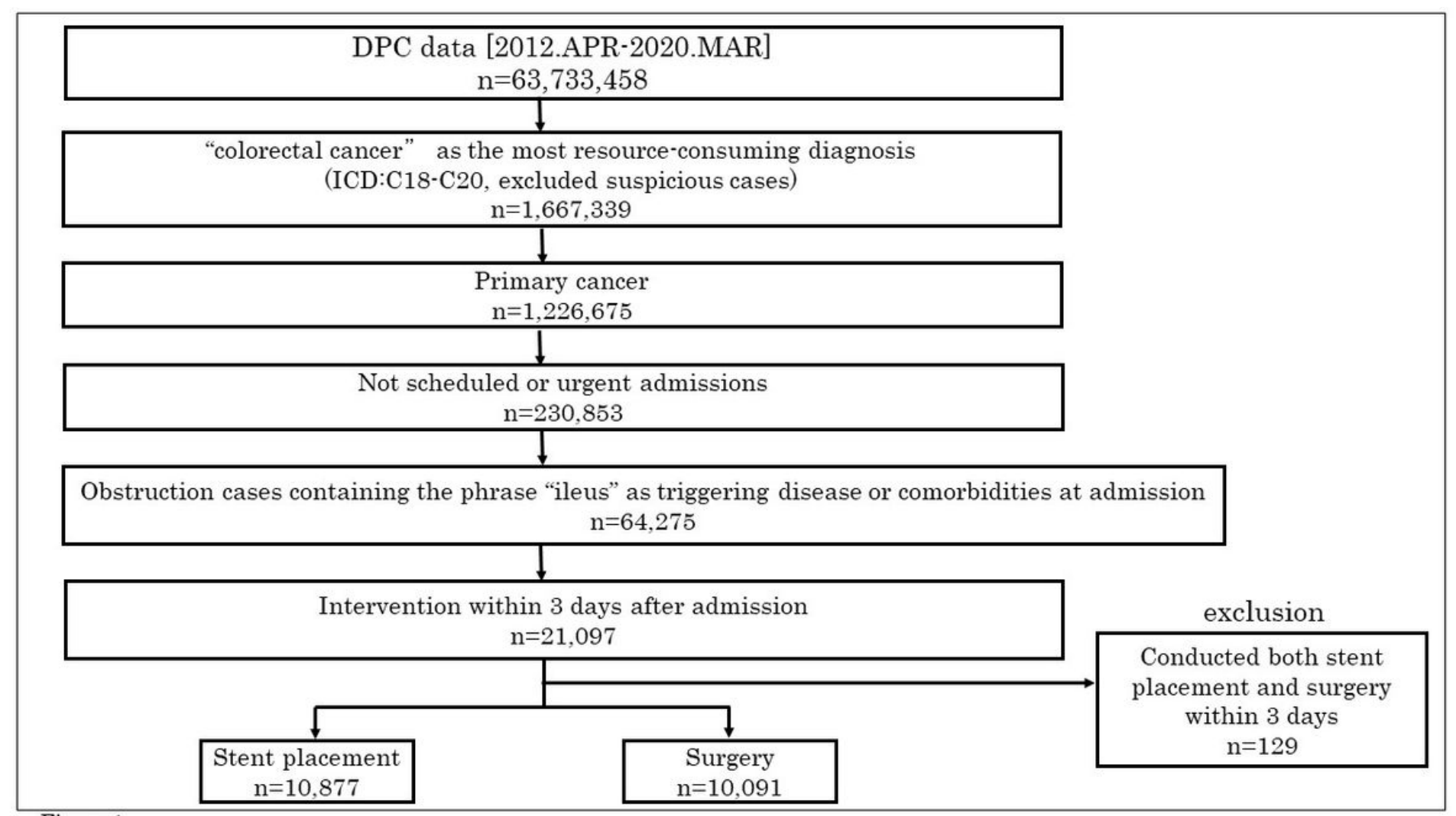

Figure 1

Figure 1

The flowchart of patient extraction. The eligible patients were extracted as per this flow. 